\title{
The Persian Version of the COVID-19 Phobia Scale (Persian-C19P-S) and the Differences in COVID-19-Related Phobic Reactions in Patients with Anxiety Disorders
}

\author{
Seyed Mehdi Samimi Ardestani ${ }^{1} \cdot$ Vahid Khosravani $^{2}$ (D) Farangis Sharifi Bastan $^{3} \cdot$ \\ Mustafa Baloğlu ${ }^{4}$
}

Accepted: 1 March 2021/ Published online: 7 April 2021

(C) The Author(s), under exclusive licence to Springer Science+Business Media, LLC, part of Springer Nature 2021

\begin{abstract}
Coronavirus disease 2019 (COVID-19) is a pandemic outbreak increasing several psychological distress, such as anxiety and phobia, and may affect patients with anxiety disorders. A scale has been recently designed to assess COVID-19-related phobic reactions named the COVID-19 Phobia Scale (C19P-S). The present study aimed to evaluate factor structure, reliability, and validity of the Persian version of the C19P-S (Persian-C19P-S) in patients with anxiety disorders and to compare COVID-19-related phobia among these patients. Three hundred patients with anxiety disorders completed the Persian-C19P-S and other scales assessing anxiety traits (e.g., the Short Health Anxiety Inventory (SHAI), the Health Concerns Questionnaire-54 (HCQ-54), and the Patient Health Questionnaire-4 (PHQ-4)) and COVID-19-related distress (e.g., the COVID Stress Scales (CSS) and the Fear of COVID-19 Scale (FCV-19)). The results showed that the Persian-C19P-S replicated the four-factor structure of the original C19P$\mathrm{S}$. Internal consistency and test-retest reliability coefficients evidenced the reliability of the scale. The validity of the scale (convergent and discriminant validity) was confirmed. Patients who had generalized anxiety and panic disorders showed higher phobic reactions related to COVID-19 than those with social anxiety disorder and specific phobia. This study indicates that the Persian version of the C19P-S is a valid scale to be used in Iranian patients with anxiety disorders to evaluate COVID-19-related phobia. Moreover, COVID-19-related phobic reactions are higher in some specific types of anxiety disorders.
\end{abstract}

Keywords COVID-19 Phobia Scale $\cdot$ Psychometric properties $\cdot$ Anxiety disorders

Vahid Khosravani

vahid.psy@gmail.com

Extended author information available on the last page of the article 


\section{Introduction}

\section{COVID-19 and Its Effects}

Coronavirus disease 2019 (COVID-19) is one of the current pandemic conditions that has affected people around the world and leads to economic, social, and psychological problems such as fear, anxiety, depression, stress, and worry (Chao et al., 2020; Lebel et al., 2020; Mertens et al., 2020; Wang et al., 2020). In addition, COVID-19 raises phobic worry, mood, reassurance-seeking/precaution, and avoidance behaviors resulting in anxiety, especially health anxiety (Asmundson \& Taylor, 2020a; Corbett et al., 2020; Dilbaz et al., 2020; Özdin \& Bayrak Özdin, 2020), and in turn affects the fear of COVID-19 (Mertens et al., 2020) and behavioral responses to the pandemic (Asmundson \& Taylor, 2020b). Fear, worry, and social vulnerabilities related to the pandemic significantly increase anxiety and depressive symptoms (Fitzpatrick et al., 2020). COVID-19 increases media use, which in turn enhances anxiety symptoms (Bendau et al., 2020). Evidence has shown that female gender, younger age, pre-existing chronic/psychiatric disorders, unemployment, high use of social media, and frequent exposure to news related to COVID-19 may increase the risk of mental distress during the pandemic (Xiong et al., 2020). Another study has reported that an unforeseen fact, endless uncertainties, avoidance behavior, loss of faith in health infrastructure, and cautious statements by international institutions are risk factors for increasing coronaphobia (Arora et al., 2020).

\section{COVID-19 and Anxiety Disorders}

Anxiety disorders accompany frequent, extreme, and intense fear and anxiety as well as behavioral dysfunctions in daily life. These disorders include generalized anxiety disorder (GAD), separation anxiety disorder, selective mutism, specific phobia (SP), social anxiety disorder (SAD), panic disorder (PD), and agoraphobia (American Psychiatric Association, 2013). People with anxiety disorders show periods of sudden and intense fear, anxiety, and horror increasing dramatically within minutes (American Psychiatric Association, 2013). Patients with anxiety disorders, who experience fear and anxiety on a daily basis, may be affected by the COVID-19 pandemic and experience more anxiety. During the COVID-19 pandemic, psychiatric disorders including anxiety disorders are reported to increase and the percentage of hospitalizations is enhanced in these patients (Luca et al., 2020). So, individuals with pre-existing anxiety are more vulnerable to experiencing higher levels of distress than non-clinical and other clinical samples (Asmundson et al., 2020). Unpredictability and uncertainty about COVID-19, ways of spreading the infection, persistence or non-persistence of the pandemic (Zandifar \& Badrfam, 2020), and perceived self-related threat related to the pandemic (Aardema, 2020) may intensify symptom severity in patients with anxiety-related disorders because these patients usually display heightened concerns about ambiguous and unpredictable risks as well as belief in the occurrence of bad events.

COVID-19 and being contaminated by it increase the risk of psychiatric disorders, especially anxiety disorders, even in individuals without a previous psychiatric history (Taquet et al., 2021). Also, individuals with anxiety-related disorders experience worsening symptoms as a result of the pandemic (Asmundson et al., 2020; Khosravani, Aardema, et al., 2021; Khosravani, Asmundson, et al., 2021). These patients experience high levels of stress, isolation, and maladaptive coping during the pandemic (Asmun dson et al. 2020). COVID- 
19 is associated with anxiety (Asmundson \& Taylor, 2020b; Jungmann \& Witthöft, 2020; McKay et al., 2020; Zhao et al., 2020) and panic symptoms (Nicomedes \& Avila, 2020). It may increase the prevalence of anxiety disorders (Shanmugam et al., 2020), especially GAD and PD (Abba-Aji et al., 2020; Frohman, Cruz, et al., 2020; Frohman, Melamed, et al., 2020; Huang \& Zhao, 2020; Islam et al., 2020; Javelot \& Weiner, 2020; Kaba \& Sari, 2020; Li et al., 2020). The COVID-19 pandemic also increases stress reactions in patients with anxiety disorders (Khosravani, Asmundson, et al., 2021) leading them to experience more anxiety (Kujawa et al., 2020). A study has shown that patients with anxiety disorders, especially those with GAD and PD, are more likely to show distressing reactions to COVID-19 (Khosravani, Asmundson, et al., 2021).

\section{COVID-19 and Coronaphobia}

The pandemic may contribute to psychopathology including COVID stress syndrome in patients with anxiety-related disorders (Asmundson et al., 2020; Khosravani, Aardema, et al., 2021; Khosravani, Asmundson, et al., 2021). Indeed, COVID-19 and its anxiety symptoms increase phobic reactions (Arpaci, Karatas, et al., 2020; Arpaci, Karataş, \& Baloğlu, 2020), phobic anxiety (Fernández et al., 2020), and coronaphobia (Mora-Magaña et al., 2020; Toprak Celenay et al., 2020) that are thought to result in anxiety-related disorders or conditions (Lee et al., 2020). So, patients with anxiety disorders are more likely to experience coronaphobia (Asmundson et al., 2020). Phobic reactions to COVID-19 are associated with pandemic-related psychopathology (Amin, 2020; Lee \& Crunk, in press). Accordingly, the validation of the scales evaluating phobic reactions, including the COVID-19 Phobia Scale (C19P-S; Arpaci, Karataş, \& Baloğlu, 2020), in patients with anxiety disorders is needed.

\section{The COVID-19 Phobia Scale (C19P-S)}

Given that COVID-19 has caused psychological distress among the public, it is necessary to validate some tools to assess this distress (Taylor \& Asmundson, 2020). During the COVID19 pandemic, researchers attempt to develop several scales including the Fear of COVID-19 Scale (FCV-19S; Ahorsu et al., 2020), the COVID Stress Scales (CSS; Taylor, Landry, et al., 2020), the Coronavirus Anxiety Scale (CAS; Lee, 2020), and the C19P-S (Arpaci, Karataş, \& Baloğlu, 2020) to assess COVID-19-related distress. The FCV-19S and the CAS are unifactorial scales, but the CSS and the C19P-S are multi-factorial measures. Among these scales, only the C19P-S is developed to assess phobic reactions suggested by the DSM-V under specific phobias (300.29).

The C19P-S is developed based on the diagnostic criteria of specific phobias (known as simple phobia) of the DSM-V and contains twenty 5-point Likert-type items. The scale measures COVID-19-related phobia on four factors: psychological (6 items; e.g., "The fear of coming down with coronavirus makes me very anxious"), psycho-somatic (5 items; e.g., "I experience serious stomachaches out of the fear of coronavirus"), economic (4 items; e.g., "The possibility of food supply shortage due to the coronavirus pandemic causes me anxiety"), and social (5 items; e.g., "I am unable to curb my anxiety of catching coronavirus from others"). The developers of the scale extracted the fourfactor structure of the C19P-S using exploratory factor analysis (EFA) which was also validated by confirmatory factor analysis (CFA). Cronbach's alphas $(\alpha)$ for the total scale $(\alpha=0.93)$ and its psychological $(\alpha=0.88)$, psycho-somatic $(\alpha=0.90)$, economic $(\alpha$ 
$=0.90)$, and social $(\alpha=0.85)$ factors have been found to be good (alphas higher than 0.70; Nunnally, 1978). In addition, the C19P-S convergent and discriminant validities were supported (Arpaci, Karataş, \& Baloğlu, 2020). In another study in the USA, Arpaci, Karatas, et al. (2020) have evaluated the psychometric properties of the CSS and showed that the CSS replicated the original four-factor structure with good validity and reliability.

\section{Aims and Hypotheses}

The present study assessed the factor structure, reliability, and validity of the Persian version of the C19P-S (Persian-C19P-S) in a clinical sample of Iranian patients with anxiety disorders and examined the differences between patients with specific types of anxiety disorders regarding COVID-19-related phobia on the C19P-S. According to the original C19P-S, we expected that the Persian-C19P-S would have a four-factor structure with good reliability and validity in Iranian patients with anxiety disorders. In addition, based on previous studies (e.g., Abba-Aji et al., 2020; Frohman, Cruz, et al., 2020; Frohman, Melamed, et al., 2020; Huang \& Zhao, 2020; Javelot \& Weiner, 2020; Kaba \& Sari, 2020; Khosravani, Asmundson, et al., 2021; Li et al., 2020), we hypothesized that GAD and PD patients would be more likely to have high COVID-19-related phobia.

\section{Methods}

\section{Participants}

Following the DSM-5 diagnostic criteria, a sample of treatment-seeking patients with principal diagnoses of anxiety disorders $(n=300$, age range $=15-65$ years, mean age $=36.12$ years, males $=41.3 \%$ ) took part in the current study. Exclusion criteria were any physical or neurological disease, substance use, psychotic disorders, and personality disorders. All clinical diagnoses were performed by a clinical psychologist and a psychiatrist based on the Structured Clinical Interview for DSM-5 Disorders, Research Version (SCID-5-RV; First et al., 2014) in the Persian version (Mohammadkhani et al., 2017). Among participants, $26.3 \%$ had a history of psychotherapy, mostly cognitive behavior therapy (CBT). The study was approved by the Medical Ethics Committee of Shahid Beheshti University of Medical Sciences (IR.SBMU.RETECH.REC.1399.825). In addition, all participants were studied based on the Helsinki Declaration and signed consent forms to participate in the study.

\section{Measures}

The C19P-S (Arpaci, Karataş, \& Baloğlu, 2020) This scale has 20 items to evaluate distress resulting from COVID-19 such as phobia using four psychological, psycho-somatic, economic, and social factors. Each item is rated on a 5-point Likert scale from 1 (completely disagree) to 5 (completely agree). The C19P-S items were independently translated from English into Persian by two expert psychologists. These Persian versions were reviewed, and a final Persian version was formed. Then, a fluent native English speaker back-translated the Persian items into English, and this English version was compared to the original English version to determine possible inconsistencies. There 
were no inconsistencies. The Persian version was also administered to 20 patients to determine the understandability of its items. Items were found completely understandable and then the Persian version along with other questionnaires was completed by the sample.

The FCV-19S (Ahorsu et al., 2020) The FCV-19S is a scale validated in Iranian samples to assess distress or fear that stemmed from COVID-19 on 7 items. The items are rated on a 5point Likert scale from 1 (completely disagree) to 5 (completely agree). Higher scores on the scale show higher levels of fear of COVID-19. Cronbach's alpha $(\alpha)$ for the scale was 0.86 in the present study.

The CSS (Taylor, Landry, et al., 2020) The CSS is a self-report measure to evaluate stress symptoms resulting from the COVID-19 pandemic and evaluates five factors of danger and contamination (12 items), socio-economic consequences (6 items), xenophobia (6 items), compulsive checking ( 6 items), and traumatic stress (6 items). The Persian version of the CSS validated in Iran (Khosravani, Asmundson, et al., 2021) with good psychometric properties was used. In the present study, the scale showed good internal consistency $(\alpha=$ $0.96)$.

The Short Health Anxiety Inventory (SHAl; Salkovskis et al., 2002) The SHAI is a selfreport tool that examines health anxiety via 18 items. Participants specify their responses on each item which includes four phrases scored from 0 to 3 . The SHAI has demonstrated good psychometric features in the Iranian population (Karimi, 2015). In this study, the scale had good reliability $(\alpha=0.96)$.

The Patient Health Questionnaire-4 (PHQ-4; Kroenke et al., 2009) This scale is a self-report questionnaire evaluating current depression and anxiety via 4 items. Two items assess depression and the other two items examine anxiety. The Persian version of the scale was validated in Iran (Ahmadi et al., 2019). Good Cronbach's alpha $(\alpha=0.86)$ was also found for the scale in the present study.

The Health Concerns Questionnaire-54 (HCQ-54; Spoth \& Dush, 1988) This scale is a 54item self-report measure assessing health-related concerns as physical, psychological, and social concerns. Participants' responses on each item are rated on a 5-point Likert scale scored from 1 (completely disagree) to 5 (completely agree). We only used the items of physical concerns ( 5 items) because the physical health-related concern is convergent for the C19P-S, especially with its somatic factor. In Iran, this scale has been examined psychometrically (Delavar et al., 2012). The internal consistency of the scale was good in the current study ( $\alpha=$ $0.80)$.

\section{Statistical Analyses}

To confirm the four-factor structure of the 20-item C19P-S, CFA using structural equation modeling (SEM) with maximum likelihood estimation (MLE) in AMOS 21.0 software (Chicago, USA) was performed. In the SEM model, model fit was tested through chi-square $\left(\chi^{2}\right)$, the comparative fit index (CFI), the Tucker-Lewis index 
(TLI), the root mean square error of approximation (RMSEA), and the standardized root mean square residual (SRMSR) detecting whether the model fit is good (RMSEA and SRMSR $<0.05$ and CFI and TLI $>0.95$ ) or acceptable (RMSEA and SRMSR between 0.05 and 0.08, and CFI and TLI between 0.90 and 0.95) (Kline, 2015; MacCallum et al., 1996; Schermelleh-Engel et al., 2003).

The reliability of the C19P-S was tested using McDonald's Omega coefficient $(\omega$; McDonald, 1985), Cronbach's alpha ( $\alpha$ ), composite reliability (CR), and test-retest reliability. McDonald's Omega coefficients were examined through Jeffrey's Amazing Statistics Program (JASP) (Love et al., 2019). CR was evaluated in SmartPLS software. Test-retest reliability of the C19P-S was performed on a subgroup of participants $(n=62)$ in a 4-week interval and the data were analyzed through Pearson correlation and intraclass correlation coefficients (ICCs) in SPSS (IBM Corp, 2013). Convergent validity of the C19P-S was evaluated via the correlations of the C19P-S with other measures using Pearson correlations in SPSS. These correlations are defined as strong $(r \geq 0.50)$, moderate ( $\mathrm{r}$ values between 0.30 and 0.49 ), and weak ( $\mathrm{r}$ values between 10 and 29) (Cohen, 1977). Also, the discriminant validity of the scale was checked through the comparison of the correlations of the C19P-S with corresponding scales than that with non-corresponding scales through conducting Steiger's Z test (Steiger, 1980). Finally, multivariate analysis of variance (MANOVA) and post hoc Tukey's HSD (honestly significant difference) test were conducted to examine possible differences among patients with specific types of anxiety disorders concerning phobia resulting from COVID-19 on the C19P-S.

\section{Results}

\section{Demographic and Clinical Characteristics}

The demographic characteristics of the participants and the means and standard deviations of variables are presented in Table 1.

\section{The Factor Structure of the C19P-S}

We tested the four-factor structure of the C19P-S using CFA. The examination of the four-factor structure of the C19P-S indicated an acceptable fit $\left(\chi^{2}=369.86, \mathrm{DF}=164\right.$, $\mathrm{CFI}=0.96, \mathrm{TLI}=0.95, \mathrm{SRMSR}=0.032, \mathrm{RMSEA}=0.065$ (90\% confidence interval $0.056-0.074)$ ) and all items of these four factors had standardized factor loadings higher than 0.40 (between 0.52 and $0.88, p<0.001$ ) (Table 2). Inter-correlations among the C19P-S subscales were statistically significant $(p<0.01)$ (Table 3$)$. Thus, as hypothesized, according to the results CFA, the C19P-S had a four-factor structure similar to the original C19P-S.

\section{Reliability of the C19P-S}

Cronbach's alpha, Omega coefficients, and CR were calculated to assess the reliability of the C19P-S. The total C19P-S $(\alpha=0.93)$ and its subscales including psychological $(\alpha=0.82)$, psycho-somatic $(\alpha=0.92)$, economic $(\alpha=0.81)$, and social $(\alpha=0.78)$ factors had good 
Cronbach's alphas. Also, Omega coefficients were 0.93, 0.82, 0.92, 0.81, and 0.79, respectively. In addition, the C19P-S subscales including psychological $(\mathrm{CR}=0.87)$, psycho-somatic $(\mathrm{CR}=0.94)$, economic $(\mathrm{CR}=0.85)$, and social $(\mathrm{CR}=0.88)$ factors had good $\mathrm{CR}(\mathrm{CR}>070$; Fornell \& Larcker, 1981).

To examine temporal stability or test-retest reliability, a subgroup of patients $(n=62)$ responded to the $\mathrm{C} 19 \mathrm{P}-\mathrm{S}$ and after a 4 -week interval, they completed the same questionnaire again and the data were analyzed through the Pearson correlation and ICCs. The results of Pearson correlation showed that test-retest coefficients for the total C19P$\mathrm{S}$, and psychological, psycho-somatic, economic, and social factors were respectively 0.95 , and $0.76,0.87,0.82$, and $0.73(p<0.01)$. In addition, ICC coefficients were 0.97 , and $0.86,0.93,0.90$, and $0.84(p<0.001)$, respectively. Therefore, these findings provided evidence regarding good reliability of the C19P-S, confirming the study hypothesis concerning the C19P-S reliability.

\section{Convergent and Discriminant Validity of the C19P-S}

Convergent validity of the C19P-S was assessed by evaluating the correlations of the C19P-S with a convergent scale (e.g., the FCV-19S), a scale assessing COVID-19-related distress (e.g.,

Table 1 Participants' characteristics

\begin{tabular}{|c|c|}
\hline Characteristics & Mean \pm S.D. or $n(\%)$ \\
\hline Age, years & $36.12 \pm 10.97$ \\
\hline Education, years & $14.03 \pm 3.09$ \\
\hline \multicolumn{2}{|l|}{ Gender } \\
\hline Male & $124(41.3 \%)$ \\
\hline Female & $176(58.7 \%)$ \\
\hline \multicolumn{2}{|l|}{ Marital status } \\
\hline Single & $119(39.7 \%)$ \\
\hline Married & $173(57.6 \%)$ \\
\hline Divorced & $8(2.7 \%)$ \\
\hline Age of onset of anxiety disorder & $30.04 \pm 10.21$ \\
\hline Duration of anxiety disorder & $6.06 \pm 4.74$ \\
\hline \multicolumn{2}{|l|}{ Type of anxiety disorders } \\
\hline Panic disorder & $80(26.7 \%)$ \\
\hline Generalized anxiety disorder & $137(45.7 \%)$ \\
\hline Social anxiety disorder & $51(17 \%)$ \\
\hline Agoraphobia & $8(2.6 \%)$ \\
\hline Special phobia & $24(8 \%)$ \\
\hline The Fear of COVID-19 Scale & $27.79 \pm 4.34$ \\
\hline The Short Health Anxiety Inventory & $33.06 \pm 10.15$ \\
\hline The Patient Health Questionnaire- 4 & $7.56 \pm 2.10$ \\
\hline The Health Concerns Questionnaire-54 physical subscale & $17.78 \pm 2.38$ \\
\hline COVID Stress Scales & $96.63 \pm 20.29$ \\
\hline The Total C19P-S & $78.32 \pm 10.03$ \\
\hline The C19P-S psychological factor & $24.61 \pm 2.96$ \\
\hline The C19P-S psycho-somatic factor & $18.24 \pm 3.90$ \\
\hline The C19P-S economic factor & $15.44 \pm 2.71$ \\
\hline The C19P-S social factor & $20.03 \pm 2.44$ \\
\hline
\end{tabular}

COVID-19 coronavirus disease 2019, C19P-S COVID-19 Phobia Scale 
Table 2 Factor loadings for 20 items of the C19P-S based on confirmatory factor analysis (CFA)

Items

Psychological factor

Q1. The fear of coming down with coronavirus makes me very anxious.

Q2. I am extremely afraid that someone in my family might become infected by the coronavirus. 0.55

Q3. News about coronavirus-related deaths causes me great anxiety.

Q4. Uncertainties surrounding coronavirus cause me enormous anxiety.

Q5. The pace that coronavirus has spread causes me great panic.

Q6. I argue passionately (or want to argue) with people I consider to be behaving irresponsibly 0.73 in the face of coronavirus.

Psycho-somatic; factor

Q7. I experience serious stomachaches out of the fear of coronavirus.

Q8. I experience serious chest pain out of the fear of coronavirus.

Q9. I experience tremors due to the fear of coronavirus.

Q10. I experience sleep problems out of the fear of coronavirus.

Q11. Coronavirus makes me so tense that I find myself unable to do the thing I previously had 0.73 no problem doing.

Economic factor

Q12. The possibility of food supply shortage due to the coronavirus pandemic causes me anxiety.

Q13. The possibility of shortages in cleaning supplies due to the coronavirus pandemic causes me anxiety.

Q14. I stock food with the fear of coronavirus.

Q15. After the coronavirus pandemic, I do not feel relaxed unless I constantly check on my supplies at home.

Social factor

Q16. After the coronavirus pandemic, I feel extremely anxious when I see people coughing.

Q17. After the coronavirus pandemic, I actively avoid people I see sneezing.

Q18. Following the coronavirus pandemic, I have noticed that I spend extensive periods of time

cleaning my hands.

Q19. The fear of coming down with coronavirus seriously impedes my social relationships. Q20. I am unable to curb my anxiety of catching coronavirus from others.

C19P-S COVID-19 Phobia Scale, $C R$ composite reliability

All factor loadings are significant $(p<0.001)$

the CSS), and other scales of anxiety-related traits (e.g., the SHAI, the HCQ-54 physical concerns, and the PHQ-4). The results of Pearson correlation showed that the C19P-S had strong correlations with the FCV-19S and the CSS $(r \geq 0.50, p<0.01)$ as well as medium-to-

Table 3 Inter-correlations among the C19P-S subscales and correlations of the total C19P-S with other scales

\begin{tabular}{llllll}
\hline Correlations between the total C19P-S and other measures & FCV-19S & SHAI & HCQ-54 & PHQ-4 & CSS \\
\hline The Total C19P-S & 0.70 & 0.54 & 0.43 & 0.49 & 0.70 \\
Inter-correlations among the C19P-S subscales & 1 & 3 & 3 & 4 & \\
1-Psychological factor & - & & & & \\
2- Psycho-somatic factor & 0.62 & - & & - \\
3- Economic factor & 0.60 & 0.70 & - \\
4- Social factor & 0.47 & 0.56 & 0.55 & - \\
\hline
\end{tabular}

C19P-S COVID-19 Phobia Scale, FCV-19S Fear of COVID-19 Scale, SHAI Short Health Anxiety Inventory, HCQ-54 Health Concerns Questionnaire-54, PHQ-4 Patient Health Questionnaire-4, CSS COVID Stress Scales All correlations are significant $(p<0.01)$ 
strong correlations with the SHAI, the HCQ-54 physical concerns, and the PHQ-4 $(p<0.01)$ (Table 3).

The C19P-S was examined in terms of discriminant validity through the comparison of the correlations of the C19P-S and its subscales with corresponding and non-corresponding scales for the C19P-S through Steiger's Z test. Given that phobia or COVID-19-related phobia may be more correlated with anxiety than depression, the correlations of the C19P-S and its subscales with scales evaluating anxiety (the PHQ-4 anxiety and the SHAI) were compared to the correlations with the PHQ-4 depression scale. Results indicated that the total C19P-S and its subscales were strongly correlated with the measures of anxiety (general anxiety and health anxiety) than the depression scale $(p<0.001$ or 0.01 or 0.05 ) (see Table 4 for more details).

To further test the discriminant validity of the C19P-S, the correlations of the C19P-S and its subscales with convergent scales for the C19P-S (e.g., the FCV-19S and the CSS) were compared to the correlations with anxiety-related trait scales (e.g., the SHAI, the HCQ-54 physical concerns, and the PHQ-4). The findings showed that the C19P-S and its subscales had stronger correlations with the corresponding scales than the correlations with anxiety-related trait scales $(p<0.001$ or 0.01 or 0.05$)$ (Table 5$)$. Therefore, the study hypothesis regarding the convergent and discriminant validity of the C19P-S was confirmed.

\section{The Comparison of COVID-19-Related Phobia Among Patients with Anxiety Disorders}

The assumptions of MANOVA showed that the data were normally distributed. Significant differences were found among patients with specific anxiety disorders regarding the C19P-S and its subscales (Wilks $\lambda=0.85 ; \mathrm{F}=3.08 ; p<0.001$ ). The results of Tukey's HSD test indicated that patients with GAD and PD significantly scored higher on the total C19P-S and its subscales than those with SAD $(p<0.001)$. PD patients significantly exceeded SP patients on the total C19P-S and its social factor $(p<0.001)$. There were no significant differences among other types (Table 6). Thus, as expected, patients with GAD and PD had high COVID-19-related phobia.

Table 4 The comparison of the correlations of the C19P-S and its subscales with anxiety-related scales than their correlations with depressive-related scale

\begin{tabular}{lllllll}
\hline & PHQ-4 anxiety & PHQ-4 depression & $Z$ & SHAI & PHQ-4 & $Z$ \\
\hline The Total C19P-S & $\mathbf{0 . 5 0}$ & $\mathbf{0 . 3 2}$ & $Z=3.35^{* * * *}$ & $\mathbf{0 . 5 4}$ & $\mathbf{0 . 3 2}$ & $Z=3.64^{* * * *}$ \\
Psychological factor & $\mathbf{0 . 4 2}$ & 0.22 & $Z=3.54^{* * *}$ & $\mathbf{0 . 5 2}$ & 0.22 & $Z=4.77^{* * *}$ \\
Psycho-somatic factor & $\mathbf{0 . 4 3}$ & $\mathbf{0 . 3 3}$ & $Z=1.82$ & $\mathbf{0 . 4 5}$ & $\mathbf{0 . 3 3}$ & $Z=1.91^{*}$ \\
Economic factor & $\mathbf{0 . 5 0}$ & $\mathbf{0 . 3 0}$ & $Z=3.7^{* * *}$ & $\mathbf{0 . 4 4}$ & $\mathbf{0 . 3 0}$ & $Z=2.21^{*}$ \\
Social factor & $\mathbf{0 . 3 2}$ & 0.19 & $Z=2.23^{*}$ & $\mathbf{0 . 3 6}$ & 0.19 & $Z=2.55^{* *}$ \\
\hline
\end{tabular}

Correlations $\geq 0.30$ in bold

C19P-S COVID-19 Phobia Scale, SHAI Short Health Anxiety Inventory, PHQ-4 Patient Health Questionnaire-4 $* p<0.05$

$* * p<0.01$

$* * * p<0.001$ 


\section{Discussion}

The study validated the Persian-C19P-S in Iranian patients with anxiety disorders and evaluated the differences among these patients with specific types of anxiety disorders regarding COVID-19-related phobia. In the present study, the results of CFA confirmed the four-factor structure of the original P19C-S. These results were similar to the original C19P-S (Arpaci, Karataş, \& Baloğlu, 2020). Therefore, this study showed that COVID-19 can create phobia as psychological, psycho-somatic, economic, and social fears in patients with anxiety disorders. The original scale has been developed and validated on healthy participants, but the present study added new evidence regarding the factor structure of the C19P-S in a clinical sample of patients with anxiety disorders. However, the C19P-S has been recently developed and validated, so further studies should examine the scale, especially in different cultures in clinical and non-clinical samples to further clarify the factor structure of the scale.

The present study showed that the Persian-C19P-S had good reliability by examining internal consistency (via Cronbach's alphas and Omega coefficients) and test-retest reliability (via Pearson correlation and CCI coefficients). All Cronbach's alpha and Omega coefficients were higher than 0.70 for the C19P-S and all its subscales, showing good reliability (Nunnally, 1978). Also, test-retest reliability coefficients calculated by Pearson correlation and CCI coefficients were higher than 0.70 for the scale and its subscales, confirming good temporal stability of the scale. These findings were in line with the original scale (Arpaci, Karataş, \& Baloğlu, 2020). However, in Arpaci, Karataș, and Baloğlu's (2020) study, only Cronbach's

Table 5 The comparison of the correlations of the C19P-S and its subscales with convergent measures than those with less convergent measures

\begin{tabular}{|c|c|c|c|c|}
\hline $\begin{array}{l}\text { The C19P-S and its } \\
\text { subscales }\end{array}$ & $\begin{array}{l}\text { Convergent } \\
\text { measure }\end{array}$ & $\begin{array}{l}\text { Less convergent measures } \\
\text { (anxiety-related trait } \\
\text { measures) }\end{array}$ & & \\
\hline & FCV-19S & SHAI & HCQ-54 & PHQ-4 \\
\hline The Total C19P-S & 0.70 & $\mathbf{0 . 5 4}, Z=3.86^{* * *}$ & $\mathbf{0 . 4 3}, Z=5.59 * * *$ & $\begin{array}{c}\mathbf{0 . 4 9}, Z= \\
4.76^{* * *}\end{array}$ \\
\hline Psychological factor & 0.64 & $\mathbf{0 . 5 2}, Z=2.73 * *$ & $\mathbf{0 . 3 4}, Z=5.71 * * *$ & $\begin{array}{c}\mathbf{0 . 3 8}, Z= \\
5.34 * * *\end{array}$ \\
\hline $\begin{array}{l}\text { Psycho-somatic } \\
\text { factor }\end{array}$ & 0.67 & $\mathbf{0 . 4 5}, Z=4.92^{* * *}$ & $\begin{array}{l}\mathbf{0 . 4 1}, Z= \\
0.5 .2^{* * *}\end{array}$ & $\begin{array}{l}\mathbf{0 . 4 5}, Z= \\
4.76^{* * *}\end{array}$ \\
\hline Economic factor & 0.57 & $\mathbf{0 . 4 4}, Z=2.72 * *$ & $\mathbf{0 . 4 1}, Z=3.01 * *$ & $\mathbf{0 . 4 7}, Z=2.1^{*}$ \\
\hline \multirow[t]{2}{*}{ Social factor } & 0.41 & $\mathbf{0 . 3 6}, Z=0.95$ & $0.25, Z=2.68 * *$ & $\mathbf{0 . 3 0}, Z=1.99 *$ \\
\hline & CSS & SHAI & HCQ-54 & PHQ-4 \\
\hline The Total C19P-S & 0.70 & $0.54, Z=3.77 * *$ & $\mathbf{0 . 4 3}, Z=5.75^{* *}$ & $\mathbf{0 . 4 9}, Z=4.76^{* *}$ \\
\hline Psychological factor & 0.54 & $\mathbf{0 . 5 2}, Z=0.42$ & $\mathbf{0 . 3 4}, Z=3.72 * *$ & $\mathbf{0 . 3 8}, Z=3.12 *$ \\
\hline $\begin{array}{l}\text { Psycho-somatic } \\
\text { factor }\end{array}$ & 0.63 & $\mathbf{0 . 4 5}, Z=3.82^{* *}$ & $\mathbf{0 . 4 1}, Z=4.41 * *$ & $\mathbf{0 . 4 5}, Z=3.79 * *$ \\
\hline Economic factor & 0.64 & $\mathbf{0 . 4 4}, Z=4.25^{* *}$ & $\mathbf{0 . 4 1}, Z=4.64 * *$ & $0.47, Z=3.64 * *$ \\
\hline Social factor & 0.50 & 0.36, $Z=2.69^{*}$ & $0.25, Z=4.46^{* *}$ & $\mathbf{0 . 3 0}, Z=3.74 * *$ \\
\hline
\end{tabular}

Correlations $\geq 0.30$ in bold

C19P-S COVID-19 Phobia Scale, FCV-19S Fear of COVID-19 Scale, SHAI Short Health Anxiety Inventory, HCQ-54 Health Concerns Questionnaire-54, PHQ-4 Patient Health Questionnaire-4, CSS COVID Stress Scales $* p<0.05$

$* * p<0.01$

$* * * p<0.001$ 
Table 6 Comparison of patients with specific types of anxiety disorders regarding COVID-related phobia

\begin{tabular}{|c|c|c|c|c|c|c|c|}
\hline Characteristics & $\begin{array}{l}\text { Anxiety } \\
\text { disorders } \\
\text { PD }\end{array}$ & GAD & SAD & $\mathrm{Ag}$ & SP & $\mathrm{F}$ a & Post hoc ${ }^{b}$ \\
\hline $\begin{array}{r}\text { The Total } \\
\text { C19P-S }\end{array}$ & $81.09 \pm 1.07$ & $79.46 \pm 0.82$ & $72.57 \pm 1.35$ & $78.75 \pm 3.40$ & $74.63 \pm 1.96$ & $7.60 *$ & $\begin{array}{l}\text { GAD, } \mathrm{PD}>\mathrm{SAD} \\
\mathrm{PD}>\mathrm{SP}\end{array}$ \\
\hline $\begin{array}{l}\text { Psychological } \\
\text { factor }\end{array}$ & $25.50 \pm 0.32$ & $24.77 \pm 0.24$ & $23.14 \pm 0.40$ & $25.25 \pm 1.01$ & $23.71 \pm 0.58$ & $6.12 *$ & GAD, $\mathrm{PD}>\mathrm{SAD}$ \\
\hline $\begin{array}{l}\text { Psycho-somatic } \\
\text { factor }\end{array}$ & $19.04 \pm 0.42$ & $18.66 \pm 0.32$ & $16.02 \pm 0.53$ & $19.50 \pm 1.33$ & $17.46 \pm 0.77$ & $6.22 *$ & $\mathrm{GAD}, \mathrm{PD}>\mathrm{SAD}$ \\
\hline Economic factor & $15.86 \pm 0.30$ & $15.85 \pm 0.23$ & $14.29 \pm 0.37$ & $14.13 \pm 0.93$ & $14.50 \pm 0.54$ & $5.01 *$ & $\mathrm{GAD}, \mathrm{PD}>\mathrm{SAD}$ \\
\hline Social factor & $20.69 \pm 0.27$ & $20.18 \pm 0.20$ & $19.11 \pm 0.33$ & $19.87 \pm 0.84$ & $18.96 \pm 0.49$ & $4.77 *$ & $\begin{array}{l}\mathrm{GAD}, \mathrm{PD}>\mathrm{SAD} \\
\mathrm{PD}>\mathrm{SP}\end{array}$ \\
\hline
\end{tabular}

COVID-19 coronavirus disease 2019, C19P-S COVID-19 Phobia Scale, $P D$ panic disorder, GAD generalized anxiety disorder, $S A D$ social anxiety disorder, $A g$ agoraphobia, $S P$ special phobia

${ }^{\text {a }}$ Multivariate analysis of variance (MANOVA)

$\mathrm{b}$ With the Tukey HSD

$* p<0.001$

alphas had been assessed, but the present study added new evidence in terms of confirming the temporal stability of the scale.

The current study indicated that the C19P-S had good convergent validity through its strong correlations with convergent scales (the FCV-19S evaluating the fear of COVID-19 and the CSS examining COVID-19-related stress) and other scales of anxiety-related traits. Also, the discriminant validity of the C19P-S was approved through stronger correlations of the C19P-S and its subscales with corresponding constructs for the C19P-S such as scales related to general and health anxiety than the correlations with depression because COVID-19-related phobia may be more related to anxiety than depression. Also, the greater correlations of the C19P-S and its subscales with a completely convergent scale (the FCV-19S) and a scale assessing COVID-19-related distress (the CSS) than those with measures of anxiety-related traits provided more evidence regarding the discriminant validity of the C19P-S. In Arpaci, Karataş, and Baloğlu's (2020) study, the convergent validity was evaluated through composite reliability (CR) and average variance extracted (AVE) values, and also the discriminant validity was examined through the square roots of the AVE values. However, the present study tested the convergent and discriminant validity of the scale by adding corresponding and non-corresponding measures for the C19P-S and added more evidence regarding the validity of the scale.

The present study finally showed that patients with GAD and PD experience higher COVID-19-related phobia as psychological, psycho-somatic, economic, and social fears than those with SAD and/or SP, but there were no differences among patients with GD, PD, and agoraphobia on COVID-19-related phobia. These findings were in line with previous studies (e.g., Abba-Aji et al., 2020; Frohman, Cruz, et al., 2020; Frohman, Melamed, et al., 2020; Huang \& Zhao, 2020; Javelot \& Weiner, 2020; Kaba \& Sari, 2020; Li et al., 2020), reporting that COVID-19 and its related distress may further affect GAD and PD. Also, another study has reported that those with GAD and PD are more affected by COVID-19-related stress responses than those with other types of anxiety disorders (Khosravani, Asmundson, et al., 
2021). Since COVID-19 is an acute respiratory syndrome and during this pandemic most people pay attention to their breathing, in patients with PD, the most common and central symptoms such as conditioned fear for abnormal breathing patterns and excessive attention to respiratory disorders may be exacerbated by the pandemic; therefore, PD is intensified (Javelot $\&$ Weiner, 2020). Also, patients with GAD may think too much about the COVID-19 pandemic leading to more anxiety symptoms (Huang \& Zhao, 2020) and consequently more COVID-19-related distress.

\section{Limitations}

The present study had some limitations. The study sample included treatment-seeking patients. Medication or psychotherapy may affect the experience of COVID-19-related distress. COVID-19-related phobia was only compared among patients with specific types of anxiety disorders. Accordingly, the absence of another clinical group and a group of non-clinical individuals was a limitation, which makes it impossible to discuss whether high levels of COVID-19-related phobia are specific to patients with GAD and PD or not. This study was performed on patients whose anxiety and fear are inherent in their disease, and high levels of COVID-19-related phobia may be due to the nature of their disease and not the COVID-19 pandemic itself. Therefore, studies on other clinical groups are also warranted. To collect the data, self-report questionnaires were used which may be accompanied by response bias in participants. This study was a cross-sectional design that does not allow discussing the findings causally, especially the differences between patients with specific types of anxiety disorders concerning the experience of high levels of phobia stemmed from COVID-19. Therefore, future studies should be performed longitudinally.

\section{Implications and Suggestions}

Despite these limitations, the present study has some implications. Theoretically, the study showed that COVID-19 may result in phobic reactions and the C19P-S is a valid scale to assess these phobic reactions in Iranian patients with anxiety disorders. Besides, the study suggests that phobic reactions are high in patients with GAD and PD. Therefore, the present study clinically recommends therapists to pay attention to COVID-19-related phobia when treating patients with anxiety disorders, especially those with GAD and PD.

The question to be considered here is whether the pandemic-related fear and phobia will continue after COVID-19? Therefore, it is necessary to examine this scale after the pandemic on different clinical and non-clinical groups, especially patients with anxiety disorders and obsessive-compulsive disorder, given that these two groups of patients are more likely to be further affected by COVID-19 (Asmundson et al., 2020; Rivera \& Carballea, 2020). Also, beyond the results of this study, some social recommendations must be considered. For example, COVID-19 increases depression, anxiety, and phobia. These distressing factors may increase the possibility of digital technology overuse or addictive behaviors (Estevez et al., 2020; Montag et al., 2019; Montag \& Elhai, 2020; Schivinski et al., 2020), especially during the pandemic (Elhai, McKay, et al., 2020; Elhai, Yang, et al., 2020; McKay \& Asmundson, 2020; Taylor, Paluszek, et al., 2020). Therefore, it is recommended that future studies should validate the scales measuring addictive behaviors such as gaming disorder (Pontes et al., 2019; Schivinski et al., 2018) possibly resulting from COVID-19 distress. 
Author Contribution All the authors contributed substantively to the preparation of the manuscript. All the authors contributed to and have approved the final manuscript.

Funding This research has been supported by the Behavioral Sciences Research Center, Shahid Beheshti University of Medical Sciences (SBUMS), Tehran, Iran.

\section{Declarations}

Conflict of Interest The authors declare no competing interests.

Ethical Approval The study was approved by the Medical Ethics Committee of Shahid Beheshti University of Medical Sciences. In addition, all participants were studied based on the Helsinki Declaration and they signed consent forms to participate in the study.

Informed Consent Informed consent was obtained from all participants.

\section{References}

Aardema, F. (2020). COVID-19, obsessive-compulsive disorder and invisible life forms that threaten the self. Journal of Obsessive-Compulsive and Related Disorders, 26, 100558. https://doi.org/10.1016/j.jocrd.2020. 100558.

Abba-Aji, A., Li, D., Hrabok, M., Shalaby, R., Gusnowski, A., Vuong, W., et al. (2020). COVID-19 pandemic and mental health: Prevalence and correlates of new-onset obsessive-compulsive symptoms in a Canadian province. JMIR Preprints, 1-24.

Ahmadi, S. M., Masjedi Arani, A., Bakhtiari, M., \& Davazdah Emamy, M. H. (2019). Psychometric properties of Persian Version of Patient Health Questionnaires-4 (PHQ-4) in coronary heart disease patients. Iranian Journal of Psychiatry and Behavioral Sciences, 13(4), e85820. https://doi.org/10.5812/ijpbs.85820.

Ahorsu, D. K., Lin, C. Y., Imani, V., Saffari, M., Griffiths, M. D., \& Pakpour, A. H. (2020). The fear of COVID19 scale: Development and initial validation. International Journal of Mental Health and Addiction, 1-9. https://doi.org/10.1007/s11469-020-00270-8.

American Psychiatric Association. (2013). Diagnostic and statistical manual of mental disorders. DSM-5 American Psychiatric Publishing.

Amin, S. (2020). The psychology of coronavirus fear: Are healthcare professionals suffering from coronaphobia? International Journal of Healthcare Management, 13(3), 249-256. https://doi.org/10.1080/ 20479700.2020.1765119.

Arora, A., Jha, A. K., Alat, P., \& Das, S. S. (2020). Understanding coronaphobia. Asian Journal of Psychiatry, 54, 102384. https://doi.org/10.1016/j.ajp.2020.102384.

Arpaci, I., Karataş, K., \& Baloğlu, M. (2020). The development and initial tests for the psychometric properties of the COVID-19 Phobia Scale (C19P-S). Personality and Individual Differences, 164, 110108. https://oi. org/10.1016/j.paid.2020.110108.

Arpaci, I., Karatas, K., Baloglu, M., \& Haktanir, A. (2020). COVID-19 phobia in the United States: Validation of the COVID-19 Phobia Scale (C19P-SE). Death Studies, 1-7. https://doi.org/10.1080/07481187.2020. 1848945 .

Asmundson, G. J., Paluszeka, M. M., Landrya, C. A., Rachor, G. S., McKay, D., \& Taylor, S. (2020). Do preexisting anxiety-related and mood disorders differentially impact COVID-19 stress responses and coping? Journal of Anxiety Disorders, 74, 102271. https://doi.org/10.1016/j.janxdis.2020.102271.

Asmundson, G. J., \& Taylor, S. (2020a). Coronaphobia: Fear and the 2019-nCoV outbreak. Journal of Anxiety Disorders, 70, 102196. https://doi.org/10.1016/j.janxdis.2020.102196.

Asmundson, G. J., \& Taylor, S. (2020b). How health anxiety influences responses to viral outbreaks like COVID-19: What all decision-makers, health authorities, and health care professionals need to know. Journal of Anxiety Disorders, 71, 102211. https://doi.org/10.1016/j.janxdis.2020.102211.

Bendau, A., Petzold, M. B., Pyrkosch, L., Maricic, L. M., Betzler, F., Rogoll, J., ... \& Plag, J. (2020). Associations between COVID-19 related media consumption and symptoms of anxiety, depression and COVID-19 related fear in the general population in Germany. European Archives of Psychiatry and Clinical Neuroscience, 1-9. https://doi.org/10.1007/s00406-020-01171-6 
Chao, M., Xue, D., Liu, T., Yang, H., \& Hall, B. J. (2020). Media use and acute psychological outcomes during COVID-19 outbreak in China. Journal of Anxiety Disorders, 74, 102248. https://doi.org/10.1016/j.janxdis. 2020.102248 .

Cohen, J. (1977). Statistical power analysis for the behavioral sciences. Academic Press.

Corbett, G. A., Milne, S. J., Hehir, M. P., Lindow, S. W., \& O'connell, M. P. (2020). Health anxiety and behavioural changes of pregnant women during the COVID-19 pandemic. European Journal of Obstetrics, Gynecology, and Reproductive Biology, 249, 96-97. https://doi.org/10.1016/j.ejogrb.2020.04.022.

Delavar, A., Baratian, M., Bejani, H., \& Masoudian, M. (2012). Standardization and normalization of health concerns questionnaire-54 (HCQ-54): A case study of Iranian undergraduates at university of Tehran. Educational Measurement Quarterly, 8(3), 1-37.

Dilbaz, N., Noyan, O. C., Alpar, G., \& Kazan, O. K. (2020). Development of the COVID-19 phobia scale: Validity and reliability study. The Journal of Neurobehavioral Sciences, 7(3), 142-151. https://doi.org/10. 4103/jnbs.jnbs_27_20.

Elhai, J. D., McKay, D., Yang, H., Minaya, C., Montag, C., \& Asmundson, G. J. (2020). Health anxiety related to problematic smartphone use and gaming disorder severity during COVID-19: Fear of missing out as a mediator. Human Behavior and Emerging Technologies., 3, 137-146. https://doi.org/10.1002/hbe2.227.

Elhai, J. D., Yang, H., McKay, D., \& Asmundson, G. J. (2020). COVID-19 anxiety symptoms associated with problematic smartphone use severity in Chinese adults. Journal of Affective Disorders, 274, 576-582. https://doi.org/10.1016/j.jad.2020.05.080.

Estevez, A., Jauregui, P., Lopez, N., Lopez-Gonzalez, H., \& Griffiths, M. (2020). Difficulties in emotion regulation, coping, and dysfunctional psychological symptoms in family members of people with gambling disorder. International Journal of Mental Health and Addiction, 18(5), 1196-1208. https://doi.org/10.1007/ s11469-019-00117-x.

Fernández, R. S., Crivelli, L., Guimet, N. M., Allegri, R. F., \& Pedreiraa, M. E. (2020). Psychological distress associated with COVID-19 quarantine: Latent profile analysis, outcome prediction and mediation analysis. Journal of Affective Disorders, 277, 75-84. https://doi.org/10.1016/j.jad.2020.07.133.

First, M. B., Williams, J. B. W., Karg, R. S., \& Spitzer, R. L. (2014). Structured clinical interview for DSM-5 disorders $(S C I D-5-R V)$, research version. American Psychiatric Publishing.

Fitzpatrick, K. M., Drawve, G., \& Harris, C. (2020). Facing new fears during the COVID-19 pandemic: The state of America's mental health. Journal of Anxiety Disorders, 75, 102291. https://doi.org/10.1016/j.janxdis. 2020.102291.

Fornell, C., \& Larcker, D. F. (1981). Structural equation models with unobservable variables and measurement error: Algebra and statistics. Journal of Marketing Research, 18(3), 382-388. https://doi.org/10.1177/ 002224378101800313.

Frohman, E. M., Cruz, R. A., Longmuir, R., Steinman, L., Zamvil, S. S., Villemarette-Pittman, N. R., ... \& Parsons, M. S. (2020). Part II. High-dose methotrexate with leucovorin rescue for severe COVID-19: An immune stabilization strategy for SARS-CoV-2 induced 'PANIC'attack. Journal of the Neurological Sciences, 415, 116935. https://doi.org/10.1016/j.jns.2020.116935

Frohman, E. M., Melamed, E., Cruz, R. A., Longmuir, R., Steinman, L., Zamvil, S. S., ... \& Parsons, M. S. (2020). Part I. SARS-CoV-2 triggered 'PANIC'attack in severe COVID-19. Journal of the Neurological Sciences, 415, 116936. https://doi.org/10.1016/j.jns.2020.116936

Huang, Y., \& Zhao, N. (2020). Generalized anxiety disorder, depressive symptoms and sleep quality during COVID-19 outbreak in China: A web-based cross-sectional survey. Psychiatry Research, 288, 112954. https://doi.org/10.1016/j.psychres.2020.112954.

IBM Corp. (2013). IBM Statistics for Windows, version 22. IBM Corp.

Islam, M. S., Ferdous, M. Z., \& Potenza, M. N. (2020). Panic and generalized anxiety during the COVID-19 pandemic among Bangladeshi people: An online pilot survey early in the outbreak. Journal of Affective Disorders, 276, 30-37. https://doi.org/10.1016/j.jad.2020.06.049.

Javelot, H., \& Weiner, L. (2020). Panic and pandemic: Review of the literature on the links between panic disorder and the SARS-CoV-2 epidemic. L'encephale., 46(3), S93-S98. https://doi.org/10.1016/j.encep. 2020.05.010.

Jungmann, S. M., \& Witthöft, M. (2020). Health anxiety, cyberchondria, and coping in the current COVID-19 pandemic: Which factors are related to coronavirus anxiety? Journal of Anxiety Disorders, 73, 102239. https://doi.org/10.1016/j.janxdis.2020.102239.

Kaba, D., \& Sari, B. A. (2020). Acute stress disorder with panic episodes induced by exposure to COVID-19 outbreak news in a child. Dusunen Adam: The Journal of Psychiatry and Neurological Sciences, 33, 1-2. https://doi.org/10.14744/DAJPNS.2020.00084.

Karimi, J. (2015). Evaluation of psychometric properties of the health anxiety inventory. Hakim Research Journal, 17(4), 297-305. 
Khosravani, V., Aardema, F., Samimi Ardestani, S. M., Sharifi Bastan, F. (2021). The impact of the coronavirus pandemic on specific symptom dimensions and severity in OCD: A comparison before and during COVID19 in the context of stress responses. Journal of Obsessive-Compulsive and Related Disorders, 100626. https://doi.org/10.1016/j.jocrd.2021.100626.

Khosravani, V., Asmundson, G. J., Taylor, S., Bastan, F. S., \& Ardestani, S. M. S. (2021). The Persian COVID stress scales (Persian-CSS) and COVID-19-related stress reactions in patients with obsessive-compulsive and anxiety disorders. Journal of Obsessive-Compulsive and Related Disorders, 28, 100615. https://doi.org/ 10.1016/j.jocrd.2020.100615.

Kline, R. B. (2015). Principles and practice of structural equation modeling. Guilford publications.

Kroenke, K., Spitzer, R. L., Williams, J. B., \& Löwe, B. (2009). An ultra-brief screening scale for anxiety and depression: The PHQ-4. Psychosomatics, 50(6), 613-621. https://doi.org/10.1016/S0033-3182(09)70864-3.

Kujawa, A., Green, H., Compas, B. E., Dickey, L., \& Pegg, S. (2020). Exposure to COVID-19 pandemic stress: Associations with depression and anxiety in emerging adults in the United States. Depression and Anxiety, 37(12), 1280-1288. https://doi.org/10.1002/da.23109.

Lebel, C., MacKinnon, A., Bagshawe, M., Tomfohr-Madsen, L., \& Giesbrecht, G. (2020). Elevated depression and anxiety symptoms among pregnant individuals during the COVID-19 pandemic. Journal of Affective Disorders, 277, 5-13. https://doi.org/10.1016/j.jad.2020.07.126.

Lee, S. A. (2020). Coronavirus Anxiety Scale: A brief mental health screener for COVID-19 related anxiety. Death Studies, 44(7), 393-401. https://doi.org/10.1080/07481187.2020.1748481.

Lee, S. A., \& Crunk, E. A. (in press). Fear and psychopathology during the COVID-19 crisis: Neuroticism, hypochondriasis, reassurance-seeking, and coronaphobia as fear factors. OMEGA-Journal of Death and Dying. https://doi.org/10.1177/0030222820949350.

Lee, S. A., Jobe, M. C., Mathis, A. A., \& Gibbons, J. A. (2020). Incremental validity of coronaphobia: Coronavirus anxiety explains depression, generalized anxiety, and death anxiety. Journal of Anxiety Disorders, 74, 102268. https://doi.org/10.1016/j.janxdis.2020.102268.

Li, Y., Duan, W., \& Chen, Z. (2020). Latent profiles of the comorbidity of post-traumatic stress disorder and generalized anxiety disorder among children and adolescents who are potentially infected with COVID-19. Children and Youth Services Review, 116, 105235. https://doi.org/10.1016/j.childyouth.2020.105235.

Love, J., Selker, R., Marsman, M., Jamil, T., Dropmann, D., Verhagen, J., ... \& Matzke, D. (2019). JASP: Graphical statistical software for common statistical designs. Journal of Statistical Software, 88(2), https:// doi.org/10.18637/jss.v088.i02

Luca, L., Ciubara, A. B., Fulga, I., Burlea, S. L., Terpan, M., \& Ciubara, A. (2020). Social implications for psychiatric pathology of depressive and anxiety disorders, alcohol addiction and psychotic disorders during the COVID-19 pandemic in Romania. Analysis of two relevant psychiatry hospitals. Revista de Cercetare si Interventie Sociala, 69, 261-272. https://doi.org/10.33788/rcis.69.16.

MacCallum, R. C., Browne, M. W., \& Sugawara, H. M. (1996). Power analysis and determination of sample size for covariance structure modeling. Psychological Methods, 1(2), 130-149. https://doi.org/10.1037//1082989x.1.2.130.

McDonald, R. P. (1985). Factor analysis and related methods. Psychology Press.

McKay, D., \& Asmundson, G. J. (2020). COVID-19 stress and substance use: Current issues and future preparations. Journal of Anxiety Disorders, 74, 102274. https://doi.org/10.1016/j.janxdis.2020.102274.

McKay, D., Yang, H., Elhai, J., \& Asmundson, G. (2020). Anxiety regarding contracting COVID-19 related to interoceptive anxiety sensations: The moderating role of disgust propensity and sensitivity. Journal of Anxiety Disorders, 73, 102233. https://doi.org/10.1016/j.janxdis.2020.102233.

Mertens, G., Gerritsen, L., Duijndam, S., Salemink, E., \& Engelhard, I. M. (2020). Fear of the coronavirus (COVID-19): Predictors in an online study conducted in March 2020. Journal of Anxiety Disorders, 74, 102258. https://doi.org/10.1016/j.janxdis.2020.102258.

Mohammadkhani, P., Ebrahimzadeh Mosavi, M., Rigi Kooteh, B., Yousefi Tapsi, M., \& Khoshdel Daryamari, S. (2017). Structured clinical interview for DSM-5 disorders, research version (SCID-5-RV)-Persian translation. University of Social Welfare and Rehabilitation Sciences Publications.

Montag, C., \& Elhai, J. D. (2020). Discussing digital technology overuse in children and adolescents during the COVID-19 pandemic and beyond: On the importance of considering affective neuroscience theory. Addictive Behaviors Reports, 12, 100313. https://doi.org/10.1016/j.abrep.2020.100313.

Montag, C., Schivinski, B., Sariyska, R., Kannen, C., Demetrovics, Z., \& Pontes, H. M. (2019). Psychopathological symptoms and gaming motives in disordered gaming-a psychometric comparison between the WHO and APA diagnostic frameworks. Journal of Clinical Medicine, 8(10), 1691. https:// doi.org/10.3390/jcm8101691.

Mora-Magaña, I., Lee, S. A., Maldonado-Castellanos, I., Jiménez-Gutierrez, C., Mendez-Venegas, J., Maya-DelMoral, A., et al. (2020). Coronaphobia among healthcare professionals in Mexico: A psychometric analysis. Death Studies, 1-10. https://doi.org/10.1080/07481187.2020.1808762. 
Nicomedes, C. J. C., \& Avila, R. M. A. (2020). An analysis on the panic during COVID-19 pandemic through an online form. Journal of Affective Disorders, 276, 14-22. https://doi.org/10.1016/j.jad.2020.06.046.

Nunnally, J. (1978). Psychometric theory. McGraw Hill.

Özdin, S., \& Bayrak Özdin, Ș. (2020). Levels and predictors of anxiety, depression and health anxiety during COVID-19 pandemic in Turkish society: The importance of gender. International Journal of Social Psychiatry, 0020764020927051. https://doi.org/10.1177/0020764020927051.

Pontes, H. M., Schivinski, B., Brzozowska-Woś, M., \& Stavropoulos, V. (2019). Laxer clinical criteria for gaming disorder may hinder future efforts to devise an efficient diagnostic approach: A tree-based model study. Journal of Clinical Medicine, 8(10), 1730. https://doi.org/10.3390/jcm8101730.

Rivera, R. M., \& Carballea, D. (2020). Coronavirus: A trigger for OCD and illness anxiety disorder? Psychological Trauma: Theory, Research, Practice, and Policy., 12, S66. https://doi.org/10.1037/ tra0000725.

Salkovskis, P. M., Rimes, K. A., Warwick, H. M. C., \& Clark, D. M. (2002). The Health Anxiety Inventory: Development and validation of scales for the measurement of health anxiety and hypochondriasis. Psychological Medicine, 32(5), 843-853. https://doi.org/10.1017/S0033291702005822.

Schermelleh-Engel, K., Moosbrugger, H., \& Müller, H. (2003). Evaluating the fit of structural equation models: Tests of significance and descriptive goodness-of-fit measures. Methods of Psychological Research Online, $8(2), 23-74$.

Schivinski, B., Brzozowska-Woś, M., Buchanan, E. M., Griffiths, M. D., \& Pontes, H. M. (2018). Psychometric assessment of the internet gaming disorder diagnostic criteria: An item response theory study. Addictive Behaviors Reports, 8, 176-184. https://doi.org/10.1016/j.abrep.2018.06.004.

Schivinski, B., Brzozowska-Wos, M. M., Stansbury, E., Satel, J., Montag, C., \& Pontes, H. M. (2020). Exploring the role of social media use motives, psychological well-being, self-esteem, and affect in problematic social media use. Frontiers in Psychology, 11, 3576. https://doi.org/10.3389/fpsyg.2020.617140.

Shanmugam, H., Juhari, J. A., Nair, P., Ken, C. S., \& Guan, N. C. (2020). Impacts of COVID-19 pandemic on mental health in Malaysia: A single thread of hope. Malaysian Journal of Psychiatry, 29(1), 1-7.

Spoth, R. L., \& Dush, D.M. (1988). The Health Concerns Questionnaire: User's guide. In Innovations in clinical practice 1988 (Vol. 7). Professional Resource Exchange Sarasota.

Steiger, J. H. (1980). Tests for comparing elements of a correlation matrix. Psychological Bulletin, 87, $245-251$. https://doi.org/10.1037//0033-2909.87.2.245.

Taquet, M., Luciano, S., Geddes, J. R., \& Harrison, P. J. (2021). Bidirectional associations between COVID-19 and psychiatric disorder: Retrospective cohort studies of 62354 COVID-19 cases in the USA. The Lancet Psychiatry, 8(2), 130-140. https://doi.org/10.1016/S2215-0366(20)30462-4.

Taylor, S., \& Asmundson, G. J. (2020). Life in a post-pandemic world: What to expect of anxiety-related conditions and their treatment. Journal of Anxiety Disorders, 72, 102231. https://doi.org/10.1016/j.janxdis. 2020.102231.

Taylor, S., Landry, C., Paluszek, M., Fergus, T. A., McKay, D., \& Asmundson, G. J. (2020). Development and initial validation of the COVID Stress Scales. Journal of Anxiety Disorders, 72, 102232. https://doi.org/10. 1016/j.janxdis.2020.102232.

Taylor, S., Paluszek, M. M., Rachor, G. S., McKay, D., \& Asmundson, G. J. (2020). Substance use and abuse, COVID-19-related distress, and disregard for social distancing: A network analysis. Addictive Behaviors, 114, 106754. https://doi.org/10.1016/j.addbeh.2020.106754.

Toprak Celenay, S., Karaaslan, Y., Mete, O., \& Ozer Kaya, D. (2020). Coronaphobia, musculoskeletal pain, and sleep quality in stay-at home and continued-working persons during the 3-month Covid-19 pandemic lockdown in Turkey. Chronobiology International, 1-8. https://doi.org/10.1080/07420528.2020.1815759.

Wang, Z. H., Yang, H. L., Yang, Y. Q., Liu, D., Li, Z. H., Zhang, X. R., ... \& Wang, X. M. (2020). Prevalence of anxiety and depression symptom, and the demands for psychological knowledge and interventions in college students during COVID-19 epidemic: A large cross-sectional study. Journal of Affective Disorders, 275, 188-193. https://doi.org/10.1016/j.jad.2020.06.034.

Xiong, J., Lipsitz, O., Nasri, F., Lui, L. M., Gill, H., Phan, L., ... \& McIntyre, R. S. (2020). Impact of COVID-19 pandemic on mental health in the general population: A systematic review. Journal of Affective Disorders, 277, 55-64. https://doi.org/10.1016/j.jad.2020.08.001.

Zandifar, A., \& Badrfam, R. (2020). Iranian mental health during the COVID-19 epidemic. Asian Journal of Psychiatry, 51, 101990. https://doi.org/10.1016/j.ajp.2020.101990.

Zhao, H., He, X., Fan, G., Li, L., Huang, Q., Qiu, Q., ... \& Xu, H. (2020). COVID-19 infection outbreak increases anxiety level of general public in China: involved mechanisms and influencing factors. Journal of Affective Disorders, 446-452. https://doi.org/10.1016/j.jad.2020.07.085 
Publisher's Note Springer Nature remains neutral with regard to jurisdictional claims in published maps and institutional affiliations.

\section{Affiliations}

\section{Seyed Mehdi Samimi Ardestani ${ }^{1} \cdot$ Vahid Khosravani $^{2} \cdot$ Farangis Sharifi Bastan $^{3}$.} Mustafa Baloğlu ${ }^{4}$

\section{Seyed Mehdi Samimi Ardestani}

mesamimi@sbmu.ac.ir

Farangis Sharifi Bastan

sharififarangis@yahoo.com

Mustafa Baloğlu

baloglu@hacettepe.edu.tr

Departments of Psychiatry, Behavioral Sciences Research Center, Imam Hossein Hospital, Shahid Beheshti University of Medical Sciences, Tehran, Iran

2 Behavioral Sciences Research Center, Shahid Beheshti University of Medical Sciences, Tehran, Iran

3 Psychosocial Injuries Research Center, Ilam University of Medical Sciences, Ilam, Iran

4 School of Education, Hacettepe University, Ankara, Turkey 